\title{
Biological transformation of PCBs in hazardous site waste sludge
}

\author{
J. Tharakan \\ Department of Chemical Engineering, Howard University, Washington, \\ $D C, U S A$
}

\begin{abstract}
In this paper we review the use of biological technologies for the treatment of PCB contaminated hazardous wastes and report on some results that have been obtained from our laboratory on the utilization of two specific biological technologies for PCB biotransformation, including a microbial amended anaerobic-aerobic cycling bioreactor and an earthworm-inoculated vermicompost bioreactor. Our review of PCB biological transformation research suggests a large potential for biological transformation of PCBs using anaerobic reductive dechlorination, with several mediating organisms and effective pathways identified. The bulk of the research demonstrates reductive dechlorination of higher chlorinated PCB congeners accompanied by the appearance of increased levels of lower chlorinated congeners. Aerobic biodegradation using cosubstrates demonstrated degradation of lower chlorinated PCBs, mostly as a cometabolic function of cosubstrate oxidation. In our laboratories, actual hazardous waste sludge contaminated with PCBs demonstrated reductions of as much as $75 \%$ in an anaerobic-aerobic bioreactor amended with PCB-dechlorinating anaerobic sediments. The addition of PCB cometabolizing aerobic microbes did not reveal significant additional PCB reductions. Our research with earthworms demonstrated PCB removals, mainly through bioaccumulation in earthworm biomass, with little evidence of further PCB biotransformation. However, these results do suggest high potential for microbial or vermicompost systems and further research is warranted to establish mechanisms and elucidate procedures for biological transformation of PCBs in hazardous sludges.
\end{abstract}

Keywords: polychlorinated biphenyls (PCBs), biotransformation, microbial, hazardous waste, earthworms. 


\section{Introduction}

Polychlorinated biphenyls (PCBs) are a family of compounds that were produced commercially by the direct chlorination of biphenyl, and there are 209 possible PCB congeners. PCBs were widely used in electrical transformers and a multitude of other industrial applications because of their excellent insulating properties, extremely low volatility and combustibility, as well as their stability and resistance to decomposition [1]. The extensive use of PCBs led to discharges that have resulted in an almost ubiquitous distribution of PCBs in the environment. The production of PCBs was banned in 1978 after accumulating evidence of their potential toxicity and carcinogenicity [2]. In the U.S. they are regulated under the Toxic Substances Control Act (TSCA) and the Comprehensive Environmental Response Compensation and Liability Act (CERCLA). Remediation of PCB contaminated sites is a national priority, but current technologies are expensive and often lead to byproducts that are environmentally problematic. Biological transformation of PCBs in hazardous waste site sludges is an attractive option because of its economic benefits and the potential for complete transformation of the waste components.

The objective if this paper is two-fold: to review the research status of biological treatment technologies for PCB contaminated sludges and to report on two biological treatment technologies that have been utilized for the remediation of PCBs in a hazardous site sludge, including an anaerobic-aerobic cycling bioreactor and a vermicompost bioreactor utilizing earthworms for the reduction of PCBs in the target sludge.

\section{Traditional treatment of PCB contaminated wastes}

The most common approved treatment technology for PCB contaminated wastes are land filling or incineration. Complete destruction of PCBs requires incineration at a temperature of $1200^{\circ} \mathrm{C}$. Combustion at temperatures below this often leads to the generation of dioxins and other hazardous emissions. Hence, the degree of acceptance by the public for this technology is low; in addition, the high cost of incineration of around $\$ 2,300$ per ton [3] renders it economically non-viable in most instances. Land filling of PCB contaminated sludges, soils and sediments is also an approved method of disposal [3], although there is opposition to this procedure due to the potential for PCB volatilization as well as escape of PCB through leaching and contamination of groundwater. Land filling also only contains the PCB contaminated wastes - actual elimination of PCBs does not occur. Finally, both these technologies are strictly ex situ technologies that require the excavation and transport of the PCB contaminated wastes. In the case of PCB contaminated sediments, dredging is especially troublesome as it results in the re-suspension of PCBs in the water and in making them more bioavailable. Excavation and dredging are also expensive technologies and project costs can be prohibitive. 


\section{Biological treatment of PCBs}

Extensive research to date has demonstrated that under anaerobic conditions, reductive dechlorination of $\mathrm{PCBs}$ occurs resulting in the reduction of levels of higher chlorinated PCB congeners and the appearance of lower chlorinated PCB congeners [4]. Under the influence of anaerobic microcosms, reductive dechlorination results in the removal of chlorines from the meta and para positions of the biphenyl molecule and a concomitant increase in the levels of mono-, di-, tri- and tetra-chlorobiphenyls [2]. Sediments from the Hudson River have demonstrated this type of dechlorination, resulting in the predominance of ortho substituted PCB congeners, and there are eight dechlorination pathways that have been elucidated [5]. It is generally believed that methanogenic and sulphate reducing bacterial populations are responsible for other dechlorination pathways, although there are indications that dehalorespiring bacteria that utilize the halogenated compound itself as the terminal electron acceptor may be responsible for some of the reductive dechlorination that has been observed in the field $[1,6]$. Several studies have identified individual microbial species that catalyze the reductive dechlorination of PCBs [7, 8].

In addition to anaerobic reductive dechlorination, aerobic biodegradation of PCBs has also been extensively investigated, beginning with the early work of Ahmed and Focht [9], who demonstrated that lightly chlorinated PCBs were degraded through the cometabolic oxidation of biphenyl through the catabolic biphenyl pathway. In this pathway, the biphenyl molecule is converted to a benzoic acid, eventually resulting in acetyl-CoA that is used in the tricarboxylic acid cycle [4]; however, the aerobic degradation of PCBs has generally been limited to trichlorobiphenyls, although more recent research has demonstrated the aerobic degradation of PCBs with as many as four or five chlorines using different cosubstrates including naphthalene and terpenes [10]. Although there are many microorganisms that code for the biphenyl pathway and hence are capable of cometabolically biodegrading PCBs, the actual mineralization of PCBs is rare. To get around this, there has been much work on the genetic engineering of microbes that can completely mineralize PCBs, and great potential has been demonstrated by some microorganisms that have demonstrated capability of attacking the resistant ortho positioned chlorine on the PCB molecule [11].

The capability of adapted anaerobic microcosms to reductively dechlorinate higher chlorinated PCB congeners and the ability of selected and/or engineered microbes to aerobically biodegrade lower chlorinated PCB congeners through cometabolic oxidation of suitable cosubstrates has lead to the investigation of cycling anaerobic-aerobic biotreatment schemes. Such a scheme in our laboratories has demonstrated the potential to reduce total PCB levels in soils spiked with a mixture of PCB congeners including Aroclor 1248 [12].

The investigation reported here utilized an anaerobic-aerobic cycling bioreactor that was amended in sequence with anaerobic sediments and then with aerobic microbes. We also report on the results of earlier investigations that utilized earthworms in a vermicomposting bioreactor to examine the potential for 
biotransformation of PCB in hazardous sludge. Both sets of investigation utilized sludge directly from a TSCA hazardous waste site and extends our earlier investigations that utilized laboratory soils spiked with PCB mixtures.

\section{Materials and methods}

\subsection{PCB Contaminated hazardous sludge}

The PCB contaminated hazardous sludge samples were from the Gary Sanitary District's in Gary, Indiana from their Ralston Street Lagoon. PCB concentrations (reported as Aroclor 1248) averaged around 180 ppm (dry weight basis), ranging as high as $1200 \mathrm{ppm}$. In the anaerobic/aerobic microbially amended bioreactor study, two separate bioreactors were established with sludge samples from two lagoon locations, Midwest and Southwest, with initial total PCB levels of 1000 and $220 \mathrm{ppm}$, respectively. In the vermicompost bioreactors the Midwest sludge sample was used.

\subsection{Anaerobic-aerobic cycling bioreactor set-up}

The reactors were constructed from modified desiccators incorporating fluid delivery plumbing with $4.5 \mathrm{~L}$ total reaction volume. An initial $1.5 \mathrm{~L}$ layer of gravel was covered with $3.0 \mathrm{~L}$ of the sludge-soil mixture. Sludge was air dried, ground and mixed with $1.5 \mathrm{~L}$ of sand. The bioreactors were operated in an anaerobic glove box; initially bioreacors were amended with $200 \mathrm{ml}$ of anaerobic sediment. Reduced anaerobic mineral media (RAMM) was circulated through the sludge mixture which was maintained under nitrogen for the duration of the anaerobic stage. Bioreactors were then switched to aerobic conditions and inoculated with Rhodococcus erythropolis (strain NY05), a gram positive aerobic cocci isolated from the Hudson River (NY). This strain has earlier demonstrated cometabolic biotransformation of several different PCBs [12]. Aerated minimal salt media (MSM) was then circulated through the bioreactor for the rest of the aerobic phase.

\subsection{Vermicompost experimental setup}

Vermicomposting bioreactors (VBs) were established with sludge volume fractions ranging from $0 \%, 10 \%, 25 \%, 50 \%$ and $75 \%(\mathrm{v} / \mathrm{v})$. Control VBs without earthworms were simultaneously initiated. Sterile potting soil was mixed with dried sludge in appropriate fractions and layered over gravel, followed by inoculation with 9 gms of earthworms. VBs were supplemented with 3 gms of cornstarch on a weekly basis. VBs were covered with mesh to prevent earthworms escaping; VB walls were covered with aluminium foil to block light and minimize PCB photodegradation. At the end total earthworm biomass in different VBs was measured. The total sludge in the VBs was also weighed and dried for extraction and analysis. The sludge-bedding matrix was dried, extracted and analyzed for PCBs. Total earthworm biomass was dried, extracted and 
analysed. This permitted the completion of the mass balance on fate and distribution of PCBs.

\subsection{PCB measurement}

Samples were air dried and then Soxhlet extracted prior to injection into gas chromatograph (HP 5890 Series II GC) utilizing a $0.32 \mathrm{~mm}$ internal diameter, $30 \mathrm{~m}$ fused silica column with a $0.5 \mu \mathrm{m}$ film ECD. Calibration curves were generated with Aroclor 1248. Protocols followed Quality Assurance Procedures established by the site regulators [13].

\section{Results and discussion}

Total PCB levels decreased over time in all VBs regardless of the sludge volume fraction. Overall reductions of around $80 \%$ were achieved [14]. The worm-free control VBs revealed that PCB levels were being reduced here as well, albeit to different levels. A mass balance model was developed in order to discriminate between PCB biotransformation, bioaccumulation and abiotic PCB removal, including irreversible adsorption to surfaces, volatilization, photodegradation, as well as PCB loss in sampling. In the calculations used in this model, volatilization and photodegradation were assumed to be negligible, due to the extremely low volatilization rates for PCBs and because VBs were lightprotected. Irreversible adsorption was assumed negligible due to rigorous extraction protocols. The total PCB mass (in $\mathrm{mg}$ ) at the outset of the vermicompost experiments and that at the end are shown in Tables 1 and 2, for VBs with and without earthworms, respectively, along with the percentage reduction of $\mathrm{PCB}$. The percentage reduction is calculated after accounting for PCB loss due to sampling and, in the case of the VBs with earthworms, bioaccumulation in the earthworm biomass. With the earthworms, there is a slight demonstrated increase in percentage PCB reduction with the earthworms present, with the largest increase in percentage reduction (14\%) seen with the VB established at a sludge fraction of $50 \%$ on a volume basis. Interestingly, the VBs with both the highest and lowest initial PCB level demonstrate no appreciable increase in PCB reduction percentages with the addition of the earthworms.

The bioaccumulation of PCBs was also measured and the data demonstrated that there was an increase in bioaccumulation as the PCB concentrations in the surrounding sludge-soil matrix increased. This data is presented in Table 3, which also includes data on the increase in earthworm biomass. This data suggests that there is some enhancement in PCB reduction with the addition of earthworms, although it is not clear how effective a strategy this may be, given the variability seen in percentage PCB reduction with different initial levels of PCB. The data on biomass increase demonstrates that the PCBs are detrimental to earthworm viability and health, contributing to significant increases in biomass reduction and viability as the PCB concentration is increased. 
Table 1: $\quad$ PCB concentrations and reductions in VBs with earthworms.

\begin{tabular}{|l|l|l|l|}
\hline $\begin{array}{l}\text { Sludge Mass } \\
\begin{array}{l}\text { Fraction } \\
(\mathrm{V} / \mathrm{V})\end{array}\end{array}$ & $\begin{array}{l}\text { Initial Total } \\
\text { PCB Mass } \\
\text { in VB }(\mathrm{mg})\end{array}$ & $\begin{array}{l}\text { Final Total } \\
\text { PCB mass } \\
\text { in VB }(\mathrm{mg})\end{array}$ & $\begin{array}{l}\text { PCB } \\
\text { Reduction* }\end{array}$ \\
\hline 10 & $10.3 \pm 0.7$ & $1.2 \pm 0.1$ & 80.9 \\
\hline 25 & $30.6 \pm 1.2$ & $3.8 \pm 0.4$ & 81.6 \\
\hline 50 & $60.3 \pm 2.5$ & $4.3 \pm 0.01$ & 90.3 \\
\hline 75 & $95.8 \pm 3.9$ & $12.3 \pm 0.7$ & 82.9 \\
\hline
\end{tabular}

*After accounting for PCB mass lost to sampling and in earthworms.

Table 2: PCB concentrations and reductions in control VBs without earthworms.

\begin{tabular}{|l|l|l|l|}
\hline $\begin{array}{l}\text { Sludge Mass } \\
\begin{array}{l}\text { Fraction } \\
(\mathrm{V} / \mathrm{V})\end{array}\end{array}$ & $\begin{array}{l}\text { Initial Total } \\
\text { PCB Mass } \\
\text { in VB }(\mathrm{mg})\end{array}$ & $\begin{array}{l}\text { Final Total } \\
\text { PCB mass } \\
\text { in VB }(\mathrm{mg})\end{array}$ & $\begin{array}{l}\text { PCB } \\
\text { Reduction* }\end{array}$ \\
\hline 10 & $9.8 \pm 0.1$ & $1.3 \pm 0.2$ & 78.7 \\
\hline 25 & $29.5 \pm 1.2$ & $2.9 \pm 0.1$ & 84.5 \\
\hline 50 & $59.8 \pm 2.4$ & $10.0 \pm 0.7$ & 77.0 \\
\hline 75 & $93.9 \pm 3.8$ & $10.9 \pm 0.2$ & 85.6 \\
\hline
\end{tabular}

*After accounting for PCB mass lost to sampling.

Table 3: $\quad$ PCB bioaccumulation and percentage earthworm biomass increase.

\begin{tabular}{|c|c|c|}
\hline $\begin{array}{l}\text { Sludge Mass } \\
\text { Fraction } \%(\mathrm{v} / \mathrm{v})\end{array}$ & $\begin{array}{lr}\text { Final PCB } & \text { Mass } \\
\text { Bioaccumulated } & \text { in } \\
\text { Earthworms } & \end{array}$ & $\begin{array}{l}\text { Final } \\
\text { Earthworm } \\
\text { Biomass } \\
\text { Increase } \\
(\%) \\
\end{array}$ \\
\hline $0 *$ & 0 & 104 \\
\hline 10 & $148 \pm 18$ & 86 \\
\hline 25 & $213+17$ & 75 \\
\hline 50 & $189 \pm 9$ & 52 \\
\hline 75 & $313+9$ & 4 \\
\hline
\end{tabular}

*Control VB with earthworms and no sludge.

In the anaerobic-aerobic cycling bioreactors, the results of these investigations have demonstrated that the bioreactor with the higher initial PCB level demonstrated a 75\% reduction in PCB level at the end of the anaerobic phase. The percentage PCB reduction that was achieved following the anaerobic phase and at the end of the aerobic phase was not significantly increased. The bioreactor with the lower initial PCB level only revealed an initial reduction of $25 \%$. Subsequent to this initial reduction in the anaerobic phase, there were no significant further reductions, even after switching the bioreactor to aerobic conditions, as has already been reported [15]. 
The extensive research on biological treatment of PCB contaminated soils has mostly focused on the use of clean soils and systems that have been spiked with varying levels and compositions of different PCB congeners. Anaerobic reductive dechlorination is the mechanism by which higher chlorinated PCB congeners get reduced in sludges and in aquatic sediments [1, 4], which occurs through the replacement of chlorine by other substituents, usually hydrogen [4]. The different dechlorination pathways that have been identified each have specificity for different congeners and different chlorination positions [2]. Aerobic degradation and ring cleavage has also been demonstrated, beginning with the investigations conducted in the early 1970s and the catabolic biphenyl pathway has been well characterized [16], but the degree of chlorination of the PCB congeners susceptible to aerobic breakdown is generally three or less.

The cycling anaerobic-aerobic bioreactors did, however, reveal changes in the composition of the PCB congeners at the end of each phase. Table 4 shows the presence or absence of particular congeners present in the sludge in the initial sludge sample, at the end of the anaerobic phase and at the end of the aerobic phase of the bioreactor study. As the data demonstrate, reductive anaerobic dechlorination does occur, while demonstrating aerobic reduction of certain congeners and recalcitrance of others.

Table 4: Presence or absence of specific PCB congeners.

\begin{tabular}{|l|l|l|l|}
\hline PCB Congener & $\begin{array}{l}\text { Present in Initial } \\
\text { Sludge }\end{array}$ & $\begin{array}{l}\text { Present at End of } \\
\text { Anaerobic Phase }\end{array}$ & $\begin{array}{l}\text { Present at End } \\
\text { of Aerobic } \\
\text { Phase }\end{array}$ \\
\hline Biphenyl & + & -- & -- \\
\hline $2,2^{\prime}$-diCB & + & -- & -- \\
\hline $4,4^{\prime}$-diCB & + & + & + \\
\hline $2,4,4^{\prime}$-triCB & + & + & + \\
\hline $2,2^{\prime}, 5$-triCB & -- & + & -- \\
\hline $2,3,4,5$-tetraCB & + & + & -- \\
\hline $2,3^{\prime}, 4^{\prime}, 5$-tetraCB & + & + & -- \\
\hline $2,3^{\prime}, 5,5$ '-tetraCB & + & + & + \\
\hline $2,2^{\prime}, 4,6$-tetraCB & + & -- & -- \\
\hline $2,2^{\prime}, 5,6^{\prime}$-tetraCB & + & + & + \\
\hline $2,2^{\prime}, 4,5^{\prime}$-tetraCB & -- & -- & + \\
\hline
\end{tabular}

The results of these investigations confirm that anaerobic dechlorination and aerobic biodegradation, when conducted in sequence, affect the PCB congener composition in the sludge. Vermicomposting results demonstrate bioaccumulation with possible biodegradation, likely due to the combined effects of earthworm gut microbial ecology and earthworm digestive actions [17-19].

\section{Conclusion}

The results from the anaerobic phase of the anaerobic/aerobic experiment showed evidence of biotransformation, likely due to amendment of sludge with 
anaerobic Hudson River sediments. The results suggest suitable amendments would support anaerobic dechlorination for biotransformation of sludge contaminated with PCBs; this may be a potentially viable option for on-site remediation.

The vermicomposting study results demonstrate earthworms can bioaccumulate PCBs from surrounding sludge in proportion to sludge PCB levels. Only minimal biotransformation of PCBs was demonstrated. However, since PCB concentrations in sludge decrease after addition of earthworms, this may be a methodology to reduce total mass of sludge requiring final disposal, especially if all the PCBs can be transported into the earthworms. As a treatment and elimination technology, vermicomposting requires further research before it can be a viable alternative for PCB removal.

\section{References}

[1] Abraham, W.R., B. Nogales, P. Golyshin, D. Pieper and K. Timmis, (2002) "PCB-Degrading Communities in Soils and Sediments, "Current Opinion Microbiology, 5 (3) 246 - 253.

[2] Wiegel, J. and Q. Wu, (2000) "Microbial Reductive Dehalogenation of PCBs" FEMS Microbial Ecology, 32 (1) 1- 15.

[3] US EPA (2003) "Management of PCBs in the USA" Office of Pollution Prevention and Toxics, Washington, DC.

[4] Bedard, D. (2003) "PCBs in Aquatic Sediments: Environmental fate and Outlook for Biological Treatment," in Haggblom and Bossert (eds) Dehalogenation: Microbial Processes and Environmental Applications, Kluwer Press, 443 - 465.

[5] Zwiernik, M., J. Quensen, and S. Boyd (1998) "FeSO4 Amendments Stimulate Extensive Anaerobic PCB Dechlorination" Environmental Science and Technology, 32 (21) 3360 - 3365.

[6] Kim, J., and G-Y Rhee (1997) "Population Dynamics of PCB Dechlorinating Microorganisms in Contaminated Sediments," Appl. Env. Microbiol. 63 (5) $1771-1776$.

[7] Cutter, L., J. Watts, K. Sowers and H. May (2001) "Identification of a Microorganism that Links its Growth to the Reductive Dechlorination of 2,3,5,6-Chlorobiphenyl" Env. Microbiol. 3 (11) 699 - 709.

[8] Wu. Q., et al (2002) "Identification of a Bacterium that Specifically Catalyzes the Reductive Dechlorination of PCBs with Double Flanked Chlorines" Appl. Env. Microbiol. 68 (2) 807 - 812.

[9] Ahmed, D., and D. Focht (1973) "Degradation of PCBs by two Species of Achromobacter" Can.J.Microbiol. 19, 47 - 52.

[10] Chawla, R.C., R. Liou, J.H. Johnson, Jr., J.P. Tharakan, "Biodegradation of PCB's in Aqueous and Soil Systems," in Wise, Trantolo, Cichon, Inyang, and Stottmeister (eds) Bioremediation of Contaminated Soils: New York, Marcel Dekker, Inc., 2000.

[11] Tsoi, T., E. Plotnikova, J. Cole, W. Guerin, M. Bagdasarian and J. Tiedje "Cloning, Expression and Nucleotide Sequence of the Pseudomonas 
aeruginosa 142 ohb Genes Coding for Oxygenolytic ortho Dehalogenation of Halobenzoates" (1999) Appl. Env. Microbiol. 65 (5) $2151-2162$.

[12] Tharakan J.P., E. Sada, R. Liou and R. C. Chawla, "Transformation of Aroclor by Indigenous and Inoculated Microbes In Slurry Reactors," in Alleman and Leeson (eds) In Situ and On-Site Bioremediation: The fifth International Symposium Proceedings, Batelle, Columbus, OH, 1999.

[13] Gary Sanitary District, Indiana. Standard Operating Procedure for the Determination of PCB's As Aroclors by GC Capillary Column Technique for Gary Sanitary District. Southwest Lab of Oklahoma, Inc., 1996.

[14] Tharakan, J., A. Addagada, D. Tomlinson, and A Shafagati, "Vermicomposting for the bioremediation of PCB Congeners in SUPERFUND site media," in Popov et al (eds) Waste Management and the Environment II, WIT Press, Southampton, UK, pp.117 - 124 (2004).

[15] Tharakan, J., D. Tomlinson, A. Addagada and S. Shafagati (2006) "Biotransformation of PCBs in Contaminated Sludge: Potential for New Biological Technologies," Engineering Life Sciences, In Press.

[16] Sylvestre, M. (2004) "Genetically Modified Organisms to Remediate PCBs: Where Do We Stand" Intl. Biodeterioration and Biodegradation, 54153 - 162.

[17] Edwards, C. A., Neuhauser, E. F., Earthworms in waste and environmental management, pp: 321-328 (1988).

[18] Fanelli et al., (1980a). Routine analysis of 2,3,7,8Tetrachlorodibenzenzo-p-dioxin in biological samples from the contaminated area of Seveso, Italy. Bull Environ Contam Toxicol 24:818823.

[19] Kreis et al., (1987). The dynamics of PCB's between earthworm populations and agricultural soils. Pedobiologia 30:379-388. 